Proceedings

\title{
Psychological Variables and Sport Practice during the Lock- down Caused by Covid-19: Comparative Analysis.
}

\author{
Marta Leyton-Román ${ }^{1 *}$ and Ruth Jiménez-Castuera ${ }^{2, *}$ \\ 1 Sports Studies Center. Rey Juan Carlos University. Madrid. Spain; marta.leyton@urjc.es \\ 2 Didactic and Behavioral Analysis in Sport Research Group. Faculty of Sports Science. University of Extre- \\ madura. Cáceres. Extremadura. Spain. ruthji@unex.es*

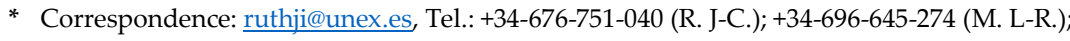

Publisher's Note: MDPI stays neutral with regard to jurisdictional claims in published maps and institutional affiliations.

\section{(c) (i)}

Copyright: $\odot 2021$ by the authors. Submitted for possible open access publication under the terms and conditions of the Creative Commons Attribution (CC BY) license (http://creativecommons.org/licenses/by/4.0/).

\begin{abstract}
The pandemic caused by the coronavirus disease, caused changes in the population in relation to the habits of physical activity and sports practice. This study analyzed motivation, commitment and self-efficacy in relation to sport practice as well as the differences depending on the employment situation and the care or not of children, during the lockdown. The study sample was conformed of 179 subjects (90 men and 89 women) between 18 and 65 years of age $(M=28.64 ; S D=10.28)$. The Behavioral Regulation in Sport Questionnaire, the Psychological Need Satisfaction in Exercise Scale, the Physical Activity Self-Efficacy scale and the Sport Commitment scale, were applied. The results have showed significant differences in favor of the population that studies and works in terms of levels of autonomous motivation and amotivation, as well as higher levels of self-efficacy, basic psychological need of competence and commitment to sport practice.
\end{abstract}

Keywords: Self-Determination Theory; self-efficacy; commitment; sport practice; employment; care children

\section{Introduction}

The global pandemic caused by the Covid-19 [1], has led to a change in routines, especially during the lockdown. This change in routines has affected ways of working and/or studying, which have been brought online in most cases, requiring a significant adaptation for most people in a short space of time. In addition to this change in routines, lockdown has affected the practice of physical activity, decreasing or eliminating it in most cases [2-3]. There are many psychological variables that affect this practice. Motivation [4], the Basic Psychological Needs (BPN) of autonomy, competence and relatedness [5], perception of self-efficacy [6] and commitment [7] have turned out to be essential variables and determinants for continuity or not with physical activity practice.

The multitude of benefits that the practice of physical activity supposes are well known [8]. Therefore, the objective of this study was to determine if there were differences between groups in different employment situations: students; workers; worker/students and retired people, in relation to these variables, as well as to determine if there were differences depending on the care or not of children, in order to establish strategies to increase the practice of physical activity.

\section{Material and methods}

2.1. Research design

An empirical, quantitative study was performed, using a descriptive populationbased study based on surveys [9].

\subsection{Participants}


The study sample was comprised of 179 Spanish subjects (90 men and 89 women) between the ages of 18 and 65 years old $(M=28.64$; $S D=10.28)$, who practiced regular physical activity. The selection criteria was that they performed physical activity at least 3 times a week and 150 minutes of moderate/vigorous physical activity, before lockdown. The exclusion criteria were not answering most of the questions and unusual response patterns, although no participants were excluded. Intentional sampling was used for sample selection [9].

\subsection{Instruments}

Motivation level: The Behavioral Regulation in Sport Questionnaire (BRSQ) by Lonsdale et al. [10] was used, validated into Spanish by Moreno-Murcia et al. [11]. This scale is composed of 36 items, which are divided into eight factors, and introduced with the phrase "I participate in this sport...": intrinsic motivation towards knowledge (e.g., "Because I like to learn how to use new techniques"), intrinsic motivation towards execution (e.g., "Because I enjoy trying to achieve long-term goals"), intrinsic motivation towards stimulation (e.g., "Because I like to learn how to use new techniques"), "Because of the positive feelings I feel while practicing this sport"), integrated regulation (e.g., "Because it allows me to live according to my values"), identified (e.g., "Because it teaches me discipline"), introjected (e.g., "Because I would feel I had failed if I abandoned it"), external (e.g., "Because if I don't do it others would be unhappy with me"), and amotivation (e.g., "However, I wonder why I strive for this"). For this study, after the factor analysis was performed, the grouping was formed according to: autonomous motivation (intrinsic motivation towards knowledge, towards execution, towards stimulation, integrated regulation and identified regulation), controlled motivation (introjected regulation and external regulation) and amotivation [12-13].

Satisfaction of basic psychological needs: The Psychological Need Satisfaction in Exercise Scale (PNSE) was used, by Wilson et al. [14]., validated into Spanish by MorenoMurcia et al. [11]. This scale is composed of 18 items, which are divided into three factors and introduced with the phrase "In my training...". These factors are autonomy, composed of six items (e.g. "I think I can choose the exercises in which I participate"), competence, composed of six items (e.g. "I feel capable of completing the most challenging exercises"), and relatedness, composed of six items (e.g. "I think I get along well with my partners when we do exercises together").

Self-efficacy: The Bandura Self-efficacy Scale was used [15]. This scale consists of 18 items that correspond to a single factor, self-efficacy (e.g. "When I don't feel physically well while training"). The questionnaire begins with the phrase "I am able to regularly sustain the training routine...".

Commitment to sports practice: The Orlick Sports Commitment Grade Scale [16] was used, validated into Spanish by Belando et al. [17]. This scale is composed of 11 items, which are divided into two factors with the opening phrase "In my trainings...": current commitment, composed of seven items (e.g. "I have made the determination not to quit even if obstacles appear (defeats, injuries, suspensions, etc.)"), and future commitment, composed of four items (e.g. "I put 100\% of my concentration and effort into the trainings, whether or not they go well").

In all of the questionnaires, answers were provided for all of the items based on a Likert Scale of 5 points, ranging from 1, which means complete disagreement, to 5, completely agree.

\subsection{Procedure}

The Google Form platform was used, so that the questionnaire could be accessed online. The questionnaire was disseminated through different channels (WhatsApp, Facebook, twitter and email). The duration of the application of the questionnaire was approximately 15 minutes. 


\subsection{Data Analysis}

After performing the Kolmogorov-Smirnov normality and variance homogeneity test by means of the Levene test, it should be noted that the results obtained from both tests show a normal distribution of the data, and therefore, parametric statistics were applied. A descriptive analysis was carried out of all the measured variables. For the tests of univariate normality, the indicators of skewness and kurtosis of variables were initially used. Curran et al. [18] establish the limits of asymmetry and kurtosis in absolute values. Values of up to 2 for skewness and 7 for kurtosis are considered normal; values between 2 and 3 for skewness and between 7 and 21 for kurtosis are considered moderately normal; and values above 7 in skewness and 21 in kurtosis are considered non-normal. For the analysis of reliability, two indices were used, Cronbach's Alpha $(\alpha)$ (equal to or greater than .70) [19], and the Omega Coefficient ( $\omega)$ [20], which also serves to check the internal consistency of the variables used in the research and, which, according to some authors [21], have shown evidence of greater accuracy. This means that in McDonald's Omega Coefficient, the established range is between 0 and 1 , with the highest values giving us the most reliable measurements [21]. With the Omega Coefficient by McDonald, the calculations were made with the "psych" 1.4.2.3 [22] of R 3.0.3 [23]. However, to consider an acceptable reliability value via the Omega Coefficient, this should be greater than .70 [24]. An ANOVA Post-Hoc analysis was carried our based on the employment situation and the care or not of children. For the analysis of the data obtained, the SPSS 23.0 statistical program was used.

\section{Results}

3.1. Descriptive and reliability analysis.

Table 1. Descriptive and reliability analysis.

\begin{tabular}{cccccccc}
\hline Variables & Range & $\mathbf{M}^{1}$ & SD $^{2}$ & Skewness & Kurtosis & $\alpha^{3}$ & $\omega^{4}$ \\
\hline BRSQ & & & & & & & \\
\hline Autonomous Motivation & $1-5$ & 4.09 & .84 & -.92 & .42 & .96 & .97 \\
\hline Controlled Motivation & $1-5$ & 1.99 & .84 & 1.01 & 1.03 & .85 & .88 \\
\hline Amotivation & $1-5$ & 1.60 & .88 & 1.76 & 3.03 & .84 & .84 \\
\hline BPNES & & & & & & \\
\hline BPN Autonomy & $1-5$ & 3.73 & .94 & -.51 & -.44 & .86 & .86 \\
\hline BPN Competence & $1-5$ & 3.96 & .93 & -.92 & .57 & .94 & .91 \\
\hline BPN Relatedness & $1-5$ & 3.45 & .93 & -.54 & -.19 & .82 & .87 \\
\hline SELF-EFFICACY & & & & & & \\
\hline Self-efficacy & $1-5$ & 3.44 & .76 & -.17 & -.28 & .93 & .71 \\
\hline SPORTS COMMITMENT & & & & & & \\
\hline Current Commitment & $1-5$ & 3.68 & .78 & -.56 & -.27 & .82 & .86 \\
\hline Future Commitment & $1-5$ & 3.20 & .87 & .08 & -.78 & .71 & .82 \\
\hline
\end{tabular}

${ }^{1} \mathrm{M}$, Media; ${ }^{2} \mathrm{SD}$, Standard Deviation; ${ }^{3} \alpha$, Cronbach`s alpha; ${ }^{4} \omega$, Omega coefficient. 


\subsection{Differential analysis.}

Regarding the care or not of children, there are no significant differences in any of the variables measured. In relation to the employment situation the results can be observed in Table 2:

Table 2. ANOVA Post-Hoc analysis by employment situation.

\begin{tabular}{|c|c|c|c|c|c|c|c|}
\hline Variables & Student & Worker & $\begin{array}{c}\text { Student } \\
\text { and } \\
\text { Worker }\end{array}$ & Retired & $p^{1}$ & $\begin{array}{c}\text { Root } \\
\text { mean } \\
\text { square }\end{array}$ & $F$ \\
\hline Autonomous Motivation & $4.23 \pm .77^{*}$ & $3.85 \pm .91^{*}$ & $4.60 \pm .40^{*}$ & $3.96 \pm .81$ & .00 & 4.69 & 7.22 \\
\hline Controlled Motivation & $1.95 \pm .77$ & $1.98 \pm .89$ & $2.05 \pm .89$ & $2.10 \pm .73$ & .94 & .88 & .12 \\
\hline Amotivation & $1.39 \pm .68^{*}$ & $1.81 \pm 1.01^{*}$ & $1.46 \pm .73$ & $1.00 \pm .00$ & .00 & 3.06 & 4.08 \\
\hline BPN Autonomy & $3.68 \pm .96$ & $3.68 \pm .95$ & $4.11 \pm .72$ & $3.25 \pm 1.32$ & .08 & 1.99 & 2.26 \\
\hline BPN Competence & $4.24 \pm .75^{*}$ & $3.74 \pm 1.00^{*}$ & $4.20 \pm .72$ & $3.55 \pm 1.33$ & .00 & 3.66 & 4.47 \\
\hline BPN Relatedness & $3.52 \pm .88$ & $3.38 \pm .97$ & $3.58 \pm .95$ & $3.25 \pm .91$ & .64 & .49 & .55 \\
\hline Self-Efficacy & $3.57 \pm .72$ & $3.28 \pm .79^{*}$ & $3.68 \pm .66^{*}$ & $3.37 \pm .80$ & .04 & 1.60 & 2.80 \\
\hline Current Commitment & $3.81 \pm .76$ & $3.53 \pm .79 *$ & $4.03 \pm .52^{*}$ & $3.14 \pm 1.08^{*}$ & .00 & 2.71 & 4.71 \\
\hline Future Commitment & $3.31 \pm .88$ & $3.08 \pm .90$ & $3.52 \pm .67^{*}$ & $2.54 \pm .57^{*}$ & .01 & 2.54 & 3.45 \\
\hline
\end{tabular}

${ }^{1} p=$ Significance $(p<.05)(p<.01)$; ${ }^{*}$ Significant differences between groups.

\section{Discussion}

According to the results, there are differences between the groups in the different employment situations. Worker/students, those who work and study at the same time, showed greater autonomous motivation, self-efficacy and current and future commitment towards the practice of physical activity. Students presented significantly more motivation towards the practice of physical activity and at the same time they were the ones who presented the highest BPN of competence.

Studies, including [25-26], have determined that physical activity helps to eliminate stress caused by other aspects such as work and study, which could support this current study in which motivation, self-efficacy and commitment to practice were higher.

Retired people, in general, presented the lowest values in all variables, with significant results in the current and future commitment to the practice of physical activity. Older people often practice physical activity outdoors or in specialized centers, and they are generally not so used to accessing technology to guide physical activity. These aspects generally affect the practice of physical activity [27] and their commitment to it.

No significant differences were found in the variables measured relating to the care or not of children. Studies such as that of Ingram et al. [28], associated living with Children with increased alcohol consumption but not with decreased physical activity. There are no studies that analyse the influence of the care or not of Children on the practice of physical activity during confinement.

Identifying the level of motivation of people and determining the influence of the context can improve interventions aimed at changing the perception of self-efficacy and commitment to physical activity practice. It would be necessary to propose physical activity programs that last over time, paying special attention to the use of strategies 
aimed at improving motivation towards sport practice, to ensure that people increase their perception of self-efficacy, dealing more effectively with situations of risk and uncertainty, such the one we live in, and to maintain and/or increase the commitment to sport practice.

Author Contributions: Conceptualization, M. L-R. and R. J-C.; methodology, M. L-R. and R. J-C.; software, M. L-R.; validation, M. L-R. and R. J-C.; formal analysis, M. L-R.; investigation, M. L-R. and R. J-C.; resources, M. L-R. and R. J-C.; data curation, M. L-R.; writing-original draft preparation, M. L-R.; writing-review and editing, M. L-R.; visualization, M. L-R. and R. J-C.; supervision, M. L-R. and R. J-C.; project administration, M. L-R. and R. J-C.

Conflicts of Interest: “The authors declare no conflict of interest."

\section{References}

1. World Health Organization (WHO). Stay physically active during self-quarantine [Internet]. Dinamarca: WHO; 2019. Available online: https://www.euro.who.int/en/healthtopics/healthemergencies/coronaviruscovid19/technicalguidance/stayphysicallyactivedur ingselfquarantine

2. Ammar, A.; Brach, M.; Trabelsi, K.; Chtourou, H.; Boukhris, O.; Masmoudi, L.; Bouaziz, B.; Bentlage, E.; How, D.; Ahmed, M.; Müller, P., et al. On Behalf of the ECLB-COVID19 Consortium. Effects of COVID-19 Home Confinement on Eating Behaviour and Physical Activity: Results of the ECLB-COVID19 International Online Survey. Nutrients, 2020, 12, 1583. doi: 10.3390/nu12061583

3. Tison, G.H.; Avram, R.; Kuhar, P.; Abreau, S.; Marcus, G.M.; Pletcher, M.J.; Olgin, J.E. Worldwide effect of COVID-19 on physical activity: A descriptive study. Ann Intern Med. 2020, 3. doi: 10.7326/M20-2665

4. Duchatelet, D.; Donche, V. Fostering self-efficacy and self-regulation in higher education: a matter of autonomy support or academic motivation?. High Educ Res Dev. 2019, 38, 733-747. doi: 10.1080/07294360.2019.1581143

5. Deci, E.L.; Ryan, R.M. The "what" and "why" of goal pursuits: Human needs and the self-determination of behavior. Psychol Inq. 2000, 11, 227-268. doi: 10.1207/S15327965PLI1104_01

6. Diego-García, M.; Zubiaur-González, M. Análisis de la percepción de autoeficacia en pilotos de parapente. Rev Psicol Deporte. 2019, 28, 41-48.

7. Podlog, L.; Gustafsson, H.; Skoog, T.; Westine. M.; Wernere, S.; Alricssonf, M. (Need satisfaction, motivation, and engagement among high-performance youth athletes: A multiple mediation analysis. Int. J Sport Exerc Psychol. 2015, 13, 1-19. doi: 10.1080/1612197X.2014.999346

8. Chan, J.S.; Liu, G.; Liang, D.; Deng, K.; Wu, J.; Yan, J.H. Special issue-therapeutic benefits of physical activity for mood: a systematic review on the effects of exercise intensity, duration, and modality. J Psychol. 2019, 153, 102-125. doi: 10.1080/00223980.2018.1470487

9. Montero, I.; León, O.G. A guide for naming research studies in Psychology. Int J Clin Health Psychol. 2007,7 , 847-862.

10. Lonsdale, C.; Hodge, K.; Rose, E.A. The Behavioral Regulation in Sport Questionnaire (BRSQ): Instrument development and initial validity evidence. J Sport Exerc Psychol. 2008, 30(3), 323-355.

11. Moreno-Murcia, J.A.; Marzo, J.C.; Martínez-Galindo, C.; Conte, L. Validación de la Escala de “Satisfacción de las Necesidades Psicológicas Básicas" y del Cuestionario de la "Regulación Conductual en el Deporte" al contexto español. RICYDE. Rev Int Cien Deporte. 2011, 26, 355-369.

12. Vansteenkiste, M.; Lens, W.; Deci, E.L. Intrinsic versus extrinsic goal contents in self-determination theory: Another look at the quality of academic motivation. Educ Psychol. 2006, 41, 19-31. doi: 10.1207/s15326985ep4101_4

13. Vansteenkiste, M.; Niemiec, C.; Soenens, B. The development of the five mini-theories of self-determination theory: An historical overview, emerging trends, and future directions. In T. Urdan \& S. Karabenick (Eds.). Advances in Motivation and Achievement, vol. 16: The decade ahead (pp.105-166). Bingley, UK: Emerald, 2010. doi: 10.1108/S0749-7423(2010)000016A007

14. Wilson, P.M.; Rogers, W.T.; Rodgers, W.M.; Wild, T.C. The Psychological Need Satisfaction in Exercise Scale. J Sport Exerc Psychol. 2006, 28, 231-251. doi: 10.1123/jsep.28.3.231

15. Bandura, A. Guide for constructing self-efficacy scales. En F. Pajares y T. C. Urdan (Eds.), Self-efficacy Beliefs of Adolescents. (2006, Vol. 5, pp. 307-337) Greenwich, CT: Information Age Publishing.

16. Orlick, T. (Entrenamiento mental: Cómo vencer en el deporte y en la vida. Barcelona: Paidotribo, 2004.

17. Belando, N.; Ferriz-Morell, R.; Moreno-Murcia, J.A. Validación de la escala de grado de compromiso deportivo en el contexto español. Eur J Hum Mov. 2012, 28, 111-124.

18. Curran, P.J.; West, S.G.; Finch, J.F. The robustness of test statistics to no normality and specification error in confirmatory factor analysis. Psychol Methods, 1996, 1, $16-29$.

19. Nunnally, J.C. Psychometric theory. New York: McGraw-Hill, 1978.

20. McDonald, R.P. Test theory. A unified treatment. Mahwah, NJ, Lawrence Erlbaum Associates, 1999.

21. Revelle, W.; Zinbarg, R.E. Coefficients Alpha, Omega, and the Gbl: Comments on Sijtsma. Psychometrika. 2009, 74, 145-154. doi: 10.1007/s11336-008-9102-z 
22. Mullan, E.; Markland, D.; Ingledew, D.K. A graded conceptualisation of selfdetermination in the regulation of exercise behaviour: Development of a measure using confirmatory factor analytic procedures. Pers Individ Differ. 1997, 23, 745-752. doi: 10.1016/S0191-8869(97)00107-4.

23. RCore-Team. R: A language and environment for statistical computing. Vienna: Austria, 2014 (Retrieved from http://www.rproject.org/).

24. Campo-Arias, A.; Oviedo, H.C. Psychometric properties of a scale: internal consistency. Rev Salud Publ. 2008, 10, 831-839. doi: 10.1590/S0124-00642008000500015

25. Tudela, A. Perceived Stress during confinement between people who practice physical exercise and those who do not. Rev Transmisión Conoc Educ Salud, 2020, 12(4), 481-494.

26. Pieh, C.; Budimir, S.; Probst, T. The effect of age, gender, income, work, and physical activity on mental health during coronavirus disease (COVID-19) lockdown in Austria. J Psychos Res. 2020, 136, 110186. Doi: 10.1016/j.jpsychores.2020.110186

27. Sannicandro, I.; Cofano, G.; Rosa, A.R.; Raiola, G. Sedentary conditions during the lockdown and movement opportunities for the Italian elderly. MOJ Sports Med, 2020, 4(3), 87-90.

28. Ingram, J.; Maciejewski, G.; Hand, C.J. Changes in diet, sleep, and physical activity are associated with differences in negative mood during COVID-19 lockdown. Frontiers in Psychol, 2020, 11, 2328. doi: 10.3389/fpsyg.2020.588604 